\title{
A framework for analyzing, comparing, and diagnosing social-ecological systems
}

\author{
$\underline{\text { Pieter W. G. Bots }}^{1}$, Maja Schlüter $^{2}$ and Jan Sendzimir $^{3}$
}

Key Words: framework development; governance system; resource system; sustainability

\section{INTRODUCTION}

Between the years 1337 and 1339, the artist Ambrogio Lorenzetti adorned the walls of the Palazzo Pubblico of Siena, Italy, with frescoes depicting allegories of good government and bad government and their effects on city and country (see Fig. 1). His imagery is lucid and effective. The "good government" fresco depicts a wise monarch surrounded by personifications of virtues such as justice, restraint, magnanimity, prudence, fortitude, and peace. The "effects" fresco shows the city of Siena and its surrounding countryside as a serene yet dynamic society: craftsmen bent to their work, women celebrating, merchants doing business, men building houses, and farmers tending their thriving fields. In sharp contrast, the "bad government" fresco shows a horned figure clad in black surrounded by epitomes of vices like perfidy, cruelty, avarice, fraud, tyranny, and war; the effects are depicted as an urban and a rural landscape dominated by ruins, fallow fields, and scenes of violence and robbery.

The reason to evoke 14th-century art in Ecology and Society is that to our eyes Lorenzetti's frescoes express three ideas that are at the heart of this special feature. The first idea is that there exists a causal relation between governance and prosperity: good governance leads to wealth, abundance, and safety; and bad governance leads to poverty, famine, and violence. The second idea is that a society prospers or suffers through the vigor and actions of individuals; governments only set the conditions. Lorenzetti paints the rulers in scenes that are separate from those depicting the effects of their ruling. Under good governance, people use their energy, skills, and natural resources in cooperative ways that accumulate wealth. Under bad governance, abuse of the same assets results in havoc. The third idea is that it is possible to diagnose governance: that one can tell good governance from bad governance not only by its effects on society, but also by examining its features.

These three 14th-century ideas are elucidated in 21st-century fashion by Elinor Ostrom, whose research has focused on the interaction between humans and natural resource systems, and in particular on the question of why some resource systems are sustainable whereas others collapse as a result of overexploitation by their users. Ostrom's (2005) analysis of the ways in which different societies have developed different institutional arrangements for natural resource management has made clear that there are no universal solutions or "panaceas" for problems of overuse or destruction of resources. Unlike Lorenzetti, Ostrom does not suggest that the distinction between good governance and bad governance can be made easily. Even if "good cop $\Rightarrow$ good crop" and "bad cop $\Rightarrow$ bad crop," the question remains as to what practices make a cop good and what practices can prevent a good crop today from jeopardizing a good crop in the future.
In two recent articles, Ostrom $(2007,2009)$ explains why it is necessary to develop cumulative capacities to diagnose the problems and potentialities of the complex social-ecological systems (SESs) in which all resources used by humans are embedded (Berkes and Folke 1998, Liu et al. 2007). Ostrom argues that to understand why some resource systems are sustainable while others collapse, the relations among multiple elements and levels of these complex systems at different spatial and temporal scales need to be identified and studied. An important barrier for such inquiry is the tendency of scientific research to focus on specific aspects or subsystems. Depending on their disciplinary background, scientists will use different concepts, theories, and models. Ostrom (2009) shows that combining findings obtained in studies of different SESs at different scales across the world using a common framework can reveal variables that affect the likelihood of self-organization in efforts to achieve a sustainable SES. She argues that such a framework will eventually allow accumulation of knowledge through systematic comparison of data obtained in a wide variety of studies on the sustainability of resource systems, and that further development of this framework is crucial for our capacity to diagnose these systems and devise strategies for sustainability.

Development of such a framework poses a big challenge. Ultimately, it would constitute a "universal language" (Carnap 1934) for SES research, and philosophers of science (Fodor 1974, Putnam 1975) have made convincing arguments against the possibility of defining such a language. However, even if we lower our sights and aim for a framework that is intersubjectively understandable for SES researchers, this will require a tremendous collaborative effort (Beers and Bots 2009). Shared understanding will occur only in an iterative process of debate and refinement. Moreover, multiple perspectives are needed to understand the complex dynamics of SESs. The framework should thus not be biased by particular theories but allow representation and comparison of observations from all studies, even when, or should we say especially when, conducted from different perspectives. However, even very general theories like panarchy theory (Gunderson and Holling 2002) entail a particular conceptualization of complex adaptive systems (Holland 1995) and assumptions about how systems behave over time. Whether these can be accommodated in a single coherent and consistent conceptual framework is an open question.

\section{THE ARTICLES}

The articles in this special feature address this question by exploring in various ways how the framework proposed by Ostrom $(2007,2009)$ can be applied and how it can be developed further. In the opening article, Michael D. McGinnis and Elinor 
Fig. 1. The Lorenzetti frescoes in the Palazzo Pubblico in Siena, Italy. From top to bottom: allegories of good and bad government, followed by their respective effects on city and country (source: Web Gallery of Art, http:// www.wga.hu/).

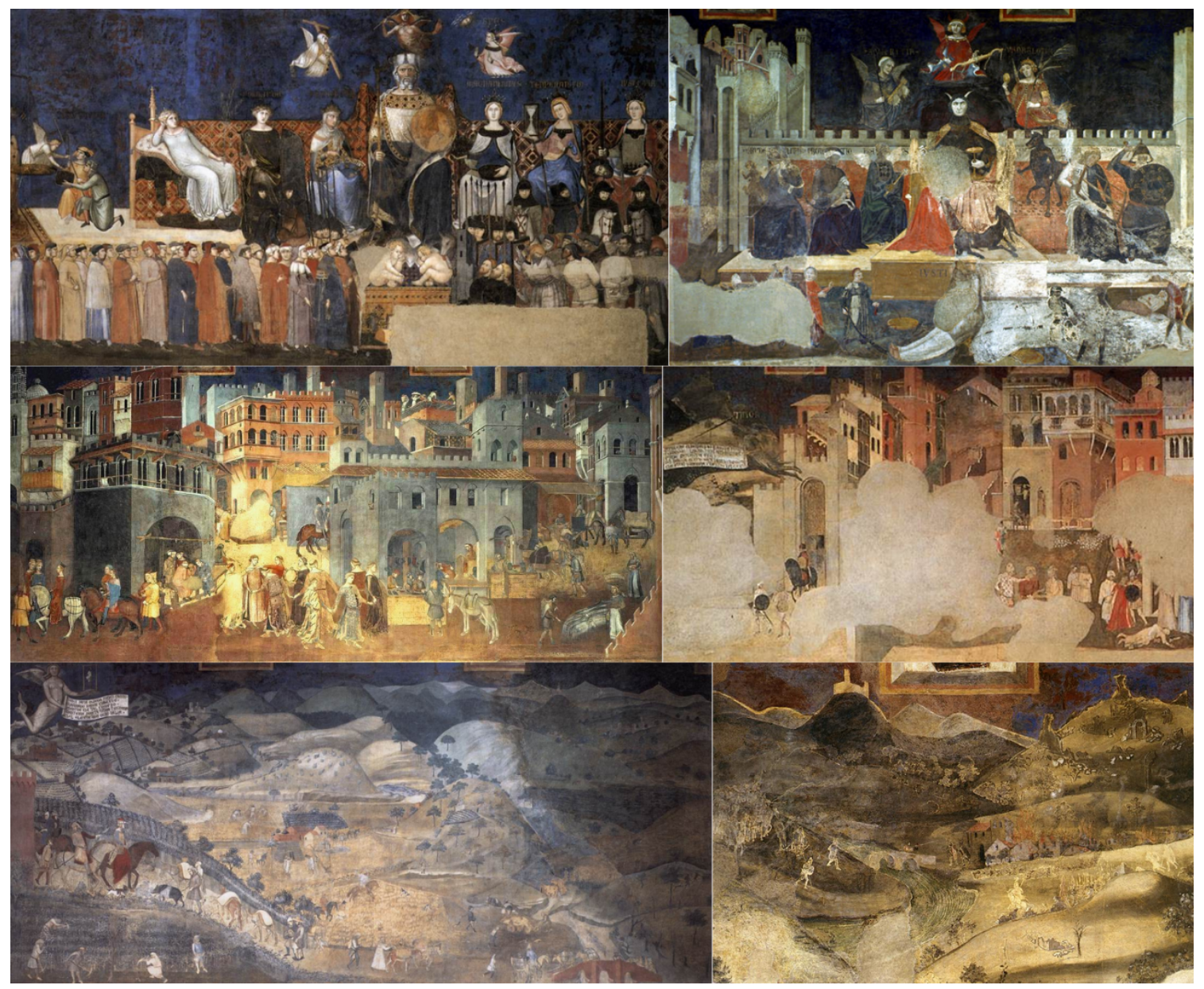

Ostrom (2014) present the SES framework and discuss recent changes as well as remaining challenges, particularly with respect to the representation of the attributes of the governance system. They also pick up the issue of application of the framework to policy settings beyond natural resource management, which was a common theme throughout the activities of the informal SES Club that led to this special issue. In concluding, they highlight the purpose of the SES framework as a foundation for organizing knowledge relevant for diagnosing the determinants of sustainability of specific SESs.

Claudia R. Binder, Jochen Hinkel, Pieter W. G. Bots, and Claudia Pahl-Wostl (2013) position the SES framework by systematically comparing it with nine other prominent frameworks used for analyzing SESs. They highlight three characteristics of frameworks for the study of social-ecological interactions, namely, their conceptualization of the relationship between the social and ecological subsystems, their perspective on the ecological system, and whether it is an action- or rather analysisoriented framework. The SES framework is classified as an integrative framework that considers two-way interactions between social and ecological systems, has an anthropocentric perspective, and is analysis oriented.

The aim of the three subsequent articles is to explore the structure and formalism of the SES framework and implications for its further development, application to case studies, and the development of dynamic models of SESs. Jochen Hinkel, Pieter W. G. Bots, and Maja Schlüter (2014) examine the framework with respect to the formal relationships between the many variables and concepts involved. They propose seven basic formal components of a framework for SESs, identify criteria for organizing concepts into tiers, and define metrics for SES outcomes. Process relationships are introduced to represent the dynamics of SESs. Increased formalization can help with resolving ambiguities as well as the further refinement and application of the SES framework.

Building on the formalization proposed by Hinkel et al. (2014), Maja Schlüter, Jochen Hinkel, Pieter W. G. Bots, and Robert Arlinghaus (2014) explore how the SES framework can facilitate a rigorous and systematic analysis of dynamic interactions within an SES. By outlining the process of constructing a dynamic model 
of resource management decision making in recreational fisheries, they show how the framework guides the "unpacking" of an SES down to the level needed to answer a given research question. They highlight the benefits of a framework-based model development process, particularly with respect to making explicit choices on model variables and relationships.

Discussion about the application of the framework to case studies in the SES Club and beyond highlighted various challenges of operationalizing the variables of the SES framework in specific case studies. To address these challenges and facilitate diagnosis of case studies, Jochen Hinkel, Michael E. Cox, Maja Schlüter, Claudia R. Binder, and Thomas Falk (2015) propose a procedure that facilitates a systematic specification of types of actors and resource systems and interactions and outcomes that are relevant for a given analytical or diagnostic question. They develop and test the procedure by systematically applying it to four different case studies.

The three articles that follow report on applications of the SES framework in empirical studies of various types of SESs. Camilla Risvoll, Gunn Elin Fedreheim, Audun Sandberg, and Shauna BurnSilver (2014) use the SES framework to identify those aspects of the governance of Norwegian national parks that may serve as sources of resilience and adaptive capacity for the natural system and the pastoral people that rely on using these areas. Ivo Baur and Claudia R. Binder (2013) proceed to investigate changes in the governance system of common property meadows in the Swiss Alps, notably changes in the operational rules that structure the focal interactions between the social and the ecological systems, which have maintained constant harvesting levels and investment activities in the past century. Finally, Harini Nagendra and Elinor Ostrom (2014) use the SES framework to investigate why some lakes in urbanized areas in Bangalore have made a successful transition while other lakes have deteriorated following urbanization.

The last article in the special issue presents a methodological innovation for SES case study comparison. Based on the SES framework and a review of the literature on the governance of common pool resource (CPR) systems, Ulrich J. Frey and Hannes Rusch (2013) propose a synthesis of 24 factors that influence whether a given CPR system achieves ecological long-term sustainability. They then proceed to test the viability of this synthesis by applying neural networks to a database holding data on 263 CPR management case studies.

\section{CHALLENGES AND FURTHER DEVELOPMENTS}

The articles in this special issue raise several issues and challenges for the future development and application of the SES framework for the diagnosis of the sustainability of SESs. First, there is a need to further develop the framework with respect to resolving ambiguities and restructuring some of the second-tier variables, particularly for the governance system (McGinnis and Ostrom 2014). The formalization introduced by Hinkel et al. (2014) is a first step toward resolving ambiguities. Application of the framework for comparison across cases and the communication of results will benefit from a more systematic and transparent interpretation of the first-tier variables such as resource unit and resource system (Hinkel et al. 2015). However, more formalization comes at a cost.
Several ideas have been raised for an expansion of the framework to address issues that cannot be captured well by the framework in its current form, such as capturing the dynamics of SESs or facilitating an analysis of the ecological dimension at levels of detail similar to institutional processes. For the former, Hinkel et al. $(2014,2015)$ and Schlüter et al. (2014) propose introducing process relationships that capture dynamics that are common across many cases, such as harvesting. The dynamics of SESs also include the dynamics of rules, for instance how changes in SESs affect changes in the governance system and vice versa as investigated for the case of Swiss pastures by Baur and Binder (2013). Further integration of ecological concepts could allow for analyses that go into equal depth for the social and ecological subsystems (Baur and Binder 2013).

A common theme across several articles is the challenge of doing justice to the complexities of real-world cases in which there is rarely only one group of rather homogenous actors that selforganize around the use of a shared CPR. Instead, multiple actors are engaged in multiple activities that depend on or affect multiple resource systems and resource units. McGinnis and Ostrom (2014) introduce multiple first-tier variables and action situations into the framework as a first step to address such complexities. They highlight the study of dynamic linkages among concurrent action situations as an important avenue for future research and refinement of the framework. Finally, Binder et al. (2013) stress the need for the development of a database for SESs to collect and share relevant data on the social and ecological systems as an important next step to support case comparisons. Several activities along those lines are currently under development by members of the group; for example, see the SES meta-analysis database project (Cox 2014).

This brief summary of the unresolved issues and ensuing challenges for further development of the SES framework shows that the quest on which we have embarked is still ongoing (see Appendix 1 for Elinor Ostrom's account of the process). Ultimately, framework refinement, development, and testing need to be a community effort and debate that involves multiple scholars who study various SESs. We hope that this special issue will invite others to apply, test, and refine the framework.

\section{Responses to this article can be read online at: http://www.ecologyandsociety.org/issues/responses. php/8051}

\section{LITERATURE CITED}

Baur, I., and Binder, C. R. 2013. Adapting to socioeconomic developments by changing rules in the governance of common property pastures in the Swiss Alps. Ecology and Society 18(4):60. http://dx.doi.org/10.5751/ES-05689-180460

Beers, P. J., and P. W. G. Bots. 2009. Eliciting conceptual models to support interdisciplinary research. Journal of Information Science 35(3):259-278. http://dx.doi.org/10.1177/0165551508099087

Berkes, F., and C. Folke. 1998. Linking social and ecological systems: management practices and social mechanisms for building resilience. Cambridge University Press, Cambridge, UK. 
Binder, C. R., J. Hinkel, P. W. G. Bots, and C. Pahl-Wostl. 2013. Comparison of frameworks for analyzing social-ecological systems. Ecology and Society 18(4):26. http://dx.doi.org/10.5751/ ES-05551-180426

Carnap, R. 1934. The unity of science. Kegan Paul, Trench, Trubner, and Co., London, UK.

Cox, M. 2014. Understanding large social-ecological systems: introducing the SESMAD project. International Journal of the Commons 8(2):265-276.

Fodor, J. A. 1974. Special sciences (or: the disunity of science as a working hypothesis). Synthese 28:97-115. http://dx.doi. org/10.1007/BF00485230

Frey, U. J., and H. Rusch. 2013. Using artificial neural networks for the analysis of social-ecological systems. Ecology and Society 18(2):40. http://dx.doi.org/10.5751/ES-05202-180240

Gunderson, L. H., and C. S. Holling, editors. 2002. Panarchy: understanding transformations in human and natural systems. Island, Washington, D.C., USA.

Hinkel, J., P. W. G. Bots, and M. Schlüter. 2014. Enhancing the Ostrom social-ecological system framework through formalization. Ecology and Society 19(3):51. http://dx.doi.org/10.5751/ ES-06475-190351

Hinkel, J., M. E. Cox, M. Schlüter, C. R. Binder, and T. Falk. 2015. A diagnostic procedure for applying the social-ecological systems framework in diverse cases. Ecology and Society 20(1):32. http://dx.doi.org/10.5751/ES-07023-200132

Holland, J. H. 1995. Hidden order: how adaptation builds complexity. Helix Books, Addison-Wesley, Reading, Massachusetts, USA.

Liu, J., T. Dietz, S. R. Carpenter, M. Alberti, C. Folke, E. Moran, A. N. Pell, P. Deadman, T. Kratz, J. Lubchenco, E. Ostrom, Z. Ouyang, W. Provencher, C. L. Redman, S. H. Schneider, and W. W. Taylor. 2007. Complexity of coupled human and natural systems. Science 317:1513-1516. http://dx.doi.org/10.1126/ science. 1144004

McGinnis, M. D., and E. Ostrom. 2014. Social-ecological system framework: initial changes and continuing challenges. Ecology and Society 19(2):30. http://dx.doi.org/10.5751/ES-06387-190230

Nagendra, H., and E. Ostrom. 2014. Applying the socialecological system framework to the diagnosis of urban lake commons in Bangalore, India. Ecology and Society 19(2):67. http://dx.doi.org/10.5751/ES-06582-190267

Ostrom, E. 2005. Understanding institutional diversity. Princeton University Press, Princeton, New Jersey, USA.

Ostrom, E. 2007. A diagnostic approach for going beyond panaceas. Proceedings of the National Academy of Sciences of the United States of America 104(39):15181-15187. http://dx.doi. org/10.1073/pnas.0702288104

Ostrom, E. 2009. A general framework for analyzing sustainability of social-ecological systems. Science 325:419-422. http://dx.doi.org/10.1126/science.1172133
Putnam, H. 1975. The nature of mental states. Pages 429-440 in H. Putnam, editor. Mind, language and reality. Philosophical Papers, Volume 2. Cambridge University Press, Cambridge, UK. http://dx.doi.org/10.1017/CBO9780511625251

Risvoll, C., G. Fedreheim, A. Sandberg, and S. BurnSilver. 2014. Does pastoralists' participation in the management of national parks in northern Norway contribute to adaptive governance? Ecology and Society 19(2):71. http://dx.doi.org/10.5751/ ES-06658-190271

Schlüter, M., J. Hinkel, P. W. G. Bots, and R. Arlinghaus. 2014. Application of the SES framework for model-based analysis of the dynamics of social-ecological systems. Ecology and Society 19(1):36. http://dx.doi.org/10.5751/ES-05782-190136 
Appendix 1. A short history of the SES Club.

Elinor Ostrom ${ }^{1}$

\section{ORIGIN}

In November of 2007, Claudia Pahl-Wostl organized an international Conference on Adaptive and Integrated Water Management (CAIWA) in Basel, Switzerland. It was attended by an outstanding group of physical and social scientists who gave a series of papers and presentations on the challenge of achieving sustainable water resources across the world. Participants were impressed with the progress that had been achieved by scholars working with Pahl-Wostl to apply the Management and Transition Framework (MTF) to the study of the transitions of a diversity of water systems in Europe under the NeWater research program.

On Saturday, November 17, after the conference was completed, Pahl-Wostl organized an informal follow-up meeting to compare the Social-Ecological System (SES) framework (that had just been published in a special feature on "Beyond Panaceas" in PNAS) to the MTF framework used in the NeWater project. She invited many of her staff and some of the other academics who had participated in the CAIWA conference including Jochen Hinkel, Andrew Ross, Maja Schlüter, and Jan Sendzimir. The participants had not yet had an opportunity to read about the SES, but they saw some immediate connections when I drew a sketch of the SES framework on a blackboard and they displayed a PowerPoint slide of the MTF framework so we could compare these frameworks side by side. We were able to identify elements of the MTF focus on water management as second-tier SES variables. Colleagues did find the discussion of alternative frameworks to be novel and invigorating. They indicated a strong interest in a follow-up meeting to explore differences and similarities in multiple frameworks that can be applied to the broad question of the sustainability of resource systems across the world. The idea germinated for a long-term project in which we would slowly improve upon the frameworks we were using at the time. We would try to develop a really strong theoretical scaffold that could be developed and used across the ecological and social sciences as a foundation for building better theories and models and testing them in a way that was understood across disciplines.

Jochen Hinkel proposed to organize a follow-up meeting at the Potsdam Institute for Climate Impact Research (PIK) in October of 2008 after participants asked when I would next be in Europe and I reported on a planned trip to Cologne on October 8. Thus, I could easily afford traveling to Berlin and then to Potsdam. It turned out that most of those attending could also plan to attend the "First SES Club Workshop" at their own cost. We invited a few other colleagues who we knew would be seriously interested in the joint development. Colleagues at PIK graciously hosted us while we engaged in our first official meeting. This started a tradition for the SES Club that we would all take care of our own travel to an agreed-upon center that would, in turn, host us in regard to good location for a meeting, hotel reservations, and our food.

Now, I will give a short history of our official meetings starting in October 2008 and extending to our last meeting in Osnabrück, Germany, in February 2012. We have found these sessions to be 
extremely interesting and important for the work we are all engaged in. A major indicator of the importance of an activity is when scholars devote their own resources to participating in joint meetings and find a variety of ways to work together to advance a serious intellectual effort. Many efforts are not initiated until someone submits a successful grant application and provide funds as an inducement to get colleagues to work together. That we have already had seven selforganized and financed meetings with substantial collaboration continuing between meetings is a true indication of the importance we all attach to this endeavor.

\section{FIRST SES CLUB WORKSHOP, POTSDAM INSTITUTE FOR CLIMATE IMPACT RESEARCH (PIK), OCTOBER 2008}

After a very pleasant dinner together, thirteen colleagues ${ }^{2}$ met at PIK all day on October 10 and at Detlef Sprinz's home for most of October 11. The objectives of the meeting were to lay out the challenges facing scholars interested in managing the environment at various spatial and temporal scales due to the lack of (1) a common ontology to bridge discourse and research across the physical and social sciences and (2) open databases that include a consistent set of relevant physical and social system variables.

In light of an intense discussion of a dozen short discussion papers as well as a detailed table providing empirical examples from the common-property systems in the Swiss Alps for many of the concepts presented in the 2007 version of the SES framework, the group came to several conclusions. First, we decided it was important to continue our efforts at each of our respective institutions and to meet once or twice a year if at all possible. Second, we named ourselves the SES Club. Third, we decided that the overall theme that would guide our efforts is "the

sustainability of social-ecological systems (SESs) or human environment systems at all scales."3 We also decided to focus on water, forestry, agriculture/pasture farming, and energy. We had a vigorous debate as to whether it was more urgent to further develop an ontology or to develop a system for spatial recording of data about resources (called GEO SES) that could be shared and updated over time so that spatial and temporal patterns could be discerned across resource types. We decided that both were needed and that we should explore existing programs that could be used to develop and share both over time. Then, we decided to meet next at the Stockholm Resilience Center in March 2009.

\section{SECOND SES CLUB MEETING, STOCKHOLM RESILIENCE CENTER, MARCH 31- APRIL 1, 2009}

The second SES Club meeting was held at the Stockholm Resilience Center with fifteen participants and multiple papers and PowerPoint presentations. ${ }^{4}$ Jochen Hinkel chaired the meeting and Jan Sendzimir recorded our discussions in substantial detail - both did outstanding jobs. We made a quick round-robin of our thinking about our efforts to develop a common diagnostic language to underlie the analysis of SESs, and to build a common geographically referenced database for specific examples of these concepts in particular locations. We discussed several existing programs that appeared to be very useful. I reported on a long discussion with David Leake, a colleague in Computer Science at Indiana University (IU), about our interest in adopting a formal ontological language for our effort. Leake strongly recommended Protégé, 
given that it was quite easy to use to represent and analyze nested conceptual systems. Protégé is freeware, open source, and widely used with many scholars who keep it current. He also strongly urged us not to restrict ourselves to one ontology since there are diverse capabilities that are useful for the kind of project we are engaged in. Other colleagues had also discussed the question of which software tools might be the most useful for our project, and there appeared to be strong support for exploring the potential usefulness of Protégé.

Colleagues reported on several empirical studies that were currently in design or in early operational form that could be drawn on and contribute to further development of the SES framework. These included the extensive studies by Pahl-Wostl and her project on multiple water systems in Europe; the study of Alpine pastures by Binder and her doctoral students; the study of diverse coastal systems under an EU grant coordinated by Sandberg; the study of the Wadden Sea and the Waterschap and waterboards in the Netherlands by Toonen; the study of diverse social-technical systems by Künneke, Bots, and Toonen at Delft; the study of recreational fisheries by Schlüter; and the study of forest resources and social systems as part of the International Forestry Resources and Institutions (IFRI) research program by Ostrom and colleagues. We agreed that as we had opportunities to revise our data collection or analysis concepts, we would try to examine the possibility of using an updated version of the SES framework for coding this work in the future so as to compare across geographical areas, resource sectors, levels, and aim to use this knowledge as we updated the framework over time.

After discussing various joint activities for the future, we agreed that one useful future strategy would be to develop a series of papers that discussed our theoretical and empirical research applying and revising the SES framework over time. Colleagues were very happy that Peter Bots and Jan Sendzimir were willing to raise the possibility of a special feature of Ecology and Society since it was both an excellent journal and well-read across multiple disciplines. We could include in such a special feature our own efforts to improve on the SES framework, to utilize a variety of tools for unpacking and repacking it and for comparing the MTF, the earlier IAD, and various parts of the SES framework in a systematic manner.

We also discussed several funding opportunities that were potentially of relevance in Europe. Pieter Bots and Rolf Kunneke discussed a draft proposal for a GeoSES database feasibility study. They pointed to the problem of a lack of a common set of methods for collecting, sharing, and publishing georeferenced data on SESs. Thus, the data sets from a variety of studies undertaken within specialized fields that are available for analysis by other scholars are often fragmented, incomplete, or obsolete. Colleagues agreed to keep their eyes open for various possibilities to fund the diagnostic approach to the study of SESs as well as the possibility of building coherent georeferenced databases in the future.

At the end of our second meeting, colleagues from Delft Technical University offered to host the third meeting of our group and explored the feasibility of several alternative dates. We all settled on the first week of November as a time that most of us could participate. Peter Bots nicely established a web page that members of the SES Club could access in order to place initial working papers and then provide a useful tool for enabling members to comment on each other's work and build tighter frameworks over time. 


\section{THIRD SES CLUB MEETING, DELFT TECHNICAL UNIVERSITY, NOVEMBER 6-7, 2009}

The first topic for our third meeting attended by a dozen scholars ${ }^{5}$ was a discussion of the special feature. Prior to the meeting, Pieter Bots and Jan Sendzimir reported that they had initiated discussions with Carl Folke, the editor of Ecology and Society, about a special feature. He was positively inclined but needed to share a written description of the proposed content with his editorial staff. Prior to our meeting, they circulated a draft proposal with a working title of "Governance of Resource Systems: Towards a Diagnostic Framework," which we discussed, made some suggestions, and approved. We also discussed various ideas that participants had regarding what they might be able to contribute and we were all then asked to write a short abstract by December 15 for what we would plan to contribute to the special feature.

That led to a productive discussion as to whether the SES framework was only useful for diagnosing problems related to resource systems. We had earlier stressed the diagnosis problem when facing complex, multitier systems. In medicine, diagnosis usually proceeds by obtaining core data about the functioning of several basic human systems and then asking further questions and doing various tests about subsystem functioning in light of the first data available. The process might then dig deeper into subsystems and sub-subsystems as information became available about the condition of the initial broader variables. I had used the title for my first published article about the framework in PNAS of "A Diagnostic Approach for Going Beyond Panaceas." I was drawing on medical history that in the last century, medical scientists had come to the firm conclusion that one could no longer think that there were simple "cure-alls" for human ills. I wanted to stress the applicability of this lesson to efforts to improve the sustainability of social-ecological systems as so many proposals were recommended as "the" optimal way of solving environmental problems.

Colleagues indicated that the SES framework could indeed be used for diagnosis, but it was also useful for cumulating knowledge about how diverse, complex systems operated and should not be used only for diagnosing problems. After a good discussion, we agreed to stop the primary focus on diagnostics and recognize the genuine value of a framework for comparing cases, theory development and testing, and potentially (though not its only value) in diagnosis. We also agreed that the framework was useful in selecting cases to be studied in depth, developing large-N databases, comparing and testing theories and models related to resources, and in helping to establish a process that would lead to the accumulation of knowledge about both SESs and STSs. Consequently, we agreed to drop the term "diagnostic" when describing the framework in general, but to continue to point out that it could productively be used for this purpose.

In an early session, Pieter Bots and Jochen Hinkel organized a "hands-on exercise in formalization" where each of us participating picked an object from the SES framework initially "user" and "resource" - which we had to define and then formalize relationships between these concepts. The process involved sequentially individual thought processes with time devoted to verbal sharing of our thoughts and then a repeat of these efforts to go further into the framework. This effort produced an excellent discussion and our recognition that the term "user" was narrower than needed for the long-run development of the framework. The term "user" related to those who were already harvesting some resource units from a resource system, but if one wanted to study outcomes one needed to study more than just the immediate users of a 
resource system. We would not refer to the members of a community living adjacent to a fishery, a forest, or a water system as users but they would be relevant for understanding some nonharvesting action situations that might lead to changes in the rules related to the SES. We agreed to start using "actor" instead of "user."

We had another serious discussion about the "disappearance" of the Action Situation from the framework as published in PNAS in 2007 and Science in 2000. I explained that in trying to keep the framework as simple as possible in its early published representations, I had assumed that the relationship between Interactions leading to Outcomes would always occur IN an action situation of diverse forms. Colleagues at the Delft meeting strongly urged that given the importance of the Action Situation in the IAD and in the MTF developed by Claudia Pahl-Wostl, we needed to work in the near future on reestablishing the Action Situation as a core part of the SES framework. As illustrated by the articles in this special feature, we have all taken this request seriously.

Mike McGinnis and I reported on our fall effort to work with our computer science colleagues to decide on which software to use in further development of the SES framework. While all agreed that Protégé would be most appropriate, they warned us to wait for a while before working on the formalization of our efforts. We still need to develop careful definitions of each concept and decide how we deal with multiple units in any particular SES examined (e.g., to study most river or irrigation systems, one also needs to include an analysis of the related land resources involved). This will affect how we program any software and is an important decision prior to a decision related to the software. Our discussion about Actors and Action Situations made it clear that we still had to work further to clarify the structure of the SES framework before investing heavily in working with Protégé or another formal program.

As a result of our discussions, we agreed that the mission of the SES Club would be:

1. To develop a common framework for the analysis of social-ecological systems (SESs) as well as social-technical systems (STSs). The development takes into account different research traditions and is meant to promote cross-sectoral and crossnational research.

2. To illustrate the multiple purposes this framework can be used in research. Intended purposes include case studies, the development of large- $\mathrm{N}$ databases, diagnosis, sustainability assessments, and the comparative analysis of theories, models, and frameworks.

3. To establish a process that leads to the cumulation of knowledge on SESs and STSs.

On the second day, we were asked to spend quiet time writing how we proposed to spend the next six months before our next SES Club meeting and thereafter. This also was a useful endeavor both because we did think carefully about what we could do and our thinking was immediately shared (verbally and in writing) among those attending. Thus, we spent some time at the end of our third meeting discussing the initial organization of future meetings. Colleagues at Delft indicated that they wanted to plan a meeting in May 2010 in conjunction with the 13th Annual International Conference on the Economics of Infrastructures they were planning for May 27-28 
at Delft. The committee wanted to focus on "The Governance of Next Generation Infrastructures: Readjusting the Political and Economic Institutions to Meet the Challenges of the 21st Century" and honor Oliver Williamson and myself at this meeting. That would enable us to organize a SES Club meeting on May 29. Those of us from Bloomington volunteered to host a fifth meeting in November of 2010, and Audun Sandberg volunteered to host a meeting toward the end of June 2011 in Norway.

\section{FOURTH SES CLUB MEETING, DELFT TECHNICAL UNIVERSITY, MAY 29, 2010}

The fourth SES Club meeting occurred after two days of a very exciting meeting on "The Governance of the Next Generation Infrastructures." The organizing committee for the annual international conference on the economics of infrastructure had done a great job of creating a series of workshops that were held on Thursday and Friday of that week. Many of us were there for the whole conference and attended workshops on a variety of resource systems where infrastructures were important, such as water systems. A group of twenty-one colleagues stayed over for a Saturday session of the SES Club. ${ }^{6}$ We went over some of the earlier decisions we had made and reaffirmed that we would continue to use "actor" rather than "user" in all of our future representations of the framework.

We spent some productive time discussing a first draft of the "meta-paper" that Jochen Hinkel, Pieter Bots, and Maja Schlüter had written, which is now in final form in this special feature. It lays out a number of key concepts related to what we mean when we formalize an argument, what an ontology is, and provides some very good examples.

We also discussed a number of ontological tools as we had at earlier meetings. Fortunately, due to the insights of Ulrich Frey, who spent the fall semester of 2010 in Bloomington, and showed us all how to use Protégé in a way consistent with our work on the SES framework, we have now adopted Protégé as one of the tools we agree we will use to develop ontologies. We leave it open to other colleagues if they find another ontological tool to be more useful.

We were also able to discuss several of the very first drafts of papers that are now in the special feature. We paid particular attention to papers discussing over-time phenomenon to examine whether the framework continued to be useful for over-time research. It was particularly helpful that we had studies from the Swiss alpine commons (Baur and Binder, 2013) as well as from Namibia (Falk et al. 2012) and Africa.

In light of several of the papers presented at this meeting, we had a long discussion as to whether the framework should focus on one of our first-level systems (e.g. Resource System, Governance System, etc.) or stress from the beginning that there might be multiple systems relevant for any particular analysis that would be undertaken in the future. Consequently, we agreed that after May 2010, in addition to changing Users to Actors, and recapturing the Action Situation, we would conceptualize all of the core working parts of the framework as potentially involving multiple systems operating at the same time or sequentially (as discussed in McGinnis and Ostrom, 2014, this special feature). An example would be different groups of farmers using the acequia irrigation systems in New Mexico (Cox 2014), who appropriate water from two Resource Systems (Surface Water and Groundwater), according to rules devised in two Governance 
Systems (state government and acequia management systems). These rules affect operationallevel Action Situations (water withdrawal and maintenance of the irrigation systems) as well as collective-level discussions of whether to change or keep current rules of their operational-level action situations). Thus, we clarified a number of very important questions for how to improve the structure of our framework to cope more effectively with the complex structures we are all studying.

We also agreed that we should simultaneously examine whether the structure of a socialecological system might be similar to that of a social-technical system (engineered systems to provide power, transportation nets, water, etc.) Both refer to settings where Actors affect Outcomes by their interaction in diverse Action Situations. Colleagues at Delft had been focusing on social-technical systems for some time and saw a direct parallel in some respects to our initial focus on social-ecological systems. Thus, we made a number of important decisions at the fourth meeting about the future of our framework so as to cover important questions related to the sustainability of human-designed systems.

\section{FIFTH SES CLUB MEETING, INDIANA UNIVERSITY, NOVEMBER 30-DECEMBER} 1,2010

The fifth meeting of our group was held in Bloomington at the Workshop in Political Theory and Policy Analysis and attended by twenty-two faculty and graduate students. ${ }^{7}$ Twelve papers were presented that covered most of the theoretical and empirical analyses that would be included in this special feature. We engaged in a vigorous discussion of all of the papers - the type of useful and in-depth discussion that is feasible when a small group of scholars from multiple disciplines have come to know and respect one another's work well, and are slowly developing common understanding of the complex world they are studying. By discussing several empirical studies as well as efforts to untangle some of our puzzles related to the structure of the SES at multiple levels, we again came to some understanding of this complex effort.

In addition to a discussion of the papers, we again discussed what papers would be needed for the special feature and agreed on internal deadlines before papers were submitted to Ecology and Society. We wanted to work on these within the SES Club to improve their quality and to use a consistent version of the SES and represent it in the first paper of the issue by McGinnis and Ostrom. We also discussed the problem of how we would keep the framework updated over time. All of us have had the sense that we were working with a broad outline that was generally agreed upon, but that we would continuously find new variables that we had not included. Then we would need to agree on whether a variable should be included, and decided that one major criteria for inclusion or not was whether the variable would be linked in at least some analyses to the question of sustainability. Further, we also will need to agree on where to put a variable in the framework (e.g. at a second, third, or fourth level). We realize that there are still further questions that would require updates from time to time. We hope to develop a web page at one of our home institutions that then carries a dated version of the framework after discussions have been held of proposed changes and most of the scholars involved in this effort have agreed to the changes. 
We held a panel at the Resilience 2011 Conference held at Arizona State University on March 12, 2011. Papers were presented by Claudia Pahl-Wostl, Camilla Risvoll-Godø, Jochen Hinkel, and Maja Schlüter. There was a full house and many excellent suggestions were made by an enthusiastic audience.

\section{SIXTH SES CLUB MEETING, UNIVERSITY OF NORDLAND, BODØ, JUNE 27-29, 2011}

The sixth meeting of our group was held in Bodø, Norway, and attended by seventeen faculty and graduate students. ${ }^{8}$ We spent the first part of the meeting discussing the Ecology and Society special issue and decided that in addition to the individual papers, it would be good to have a synthesis paper at the end of the issue that focused on a synthesis of findings from all of the papers in the issue. Pieter asked us to give him the names of suggested reviewers who are not connected to the SES Club but would be competent reviewers of papers submitted for the special issue.

We spent the afternoon of the first day dealing with a variety of definitions including the commons, frameworks, and resource units that would be relevant for both social-ecological systems and social-technological systems as well as how to develop and represent third- and fourth-tier concepts. We had long and productive discussions of a paper on metaframes by Jochen Hinkel and a second paper by Rolf Kunneke on social-technical systems. We then focused on how we could develop the framework further by setting up a wiki and posting the definitions of key terms that we planned to use. Michael Cox volunteered to help organize this process with the help of two IU graduate students during the fall semester of 2012.

After lunch, Lin gave a general talk to colleagues at the University of Nordland on the book that she had just finished with Amy Poteete and Marco Janssen on Working Together: Collective Action, the Commons, and Multiple Methods in Practice that discusses the SES framework briefly in the last section.

Then the groups discussed a variety of affiliations for the SES Club given that the IU group would be submitting a proposal to the National Science Foundation and wanted to have the SES Club involved but needed there to be a more formal entity linking all of the European research groups. Theo Toonen volunteered to have Delft University the formal home of this group and also agreed to draft an initial letter that each European participant could show to their legal department and begin the steps toward a formal home. The group then discussed the various rules that would be needed to establish this new cooperative entity, and decided to continue holding meetings twice a year and to begin appointing sets of SES members who would take on official assignments for the group between meetings.

On the second day, Michael Cox and Ulrich Frey presented their ideas for how to update the SES framework at second, third, and fourth tiers, and a lively discussion of alternative ways of proceeding followed. We then developed a set of activities that we should all undertake as a foundation for the next meeting of the SES group to be organized by Claudia Pahl-Wostl and her group in February of 2012. 


\section{SEVENTH SES CLUB MEETING IN OSNABRÜCK, FEBRUARY 13-14, 2012}

The seventh meeting of our SES Club was held in Osnabrück, Germany, on February 13-14, 2012, and was attended by twenty colleagues. ${ }^{9}$ Pieter Bots reported on the status of the papers for the special issue. If all of the papers are submitted and accepted, there will be 15 papers in the special issue. Pieter asked that we start submissions on the SES website in Giessen very soon so that he knows which papers are going to be formally submitted and can select reviewers soon.

We engaged in a long and detailed discussion of recent changes in the framework and rules we needed to follow if a new variable was introduced. All dependent lower-tier variables needed to be examined and potentially redefined. Mike McGinnis then discussed the implications of changing "user" to "actor" - including now that an actor could be either an individual or a collective actor. A stakeholder includes all other people that are exposed or affected by an Action Situation, but they do not take specific actions. We also discussed and rethought Resource Units versus Resource Services and Units and whether we should eventually replace Resource Services and Units with "Goods and Services." We decided that we needed to create a working group that would focus specifically on Resource Services and Units and how to develop a nested set of concepts that eventually included Goods and Services but not include Resource Services and Units in the version of the framework published in the special issue.

Ulrich Frey introduced us to the new SES Club webpage, http://cooperationresearch.eu/SES/. Michael Cox then introduced us to the Semantic Wiki that he and several graduate students at IU had developed. We discussed what files should be located on the web page with access to all readers and what files still needed to be restricted until general agreement on the definition was reached. Michael Cox then described the database he is developing with colleagues from the Resilience Alliance that will examine large-scale common-pool resources (CPRs) and whether the design principles that were developed to explain the robustness of small-scale CPRs also characterize robust, large-scale CPRs. Plans are to have an online wiki linked to the database with explanations of the variables and their values so that other scholars can participate in the efforts.

In the long run, we envision a process where scholars in multiple locations collaborate in the further development of a common framework for the analysis of SESs and STSs. The development will need to take different disciplinary research traditions into account and promote cross-sectoral and cross-national research. The framework will be, as far as possible, theoryneutral and applicable for multiple purposes including informing case studies, the development of large- $\mathrm{N}$ databases, diagnosis, sustainability assessment, and the comparative analysis of theories, models, and other frameworks.

The long-term process shall be facilitated by means of an open, web-based collaborative platform that allows scholars and practitioners from across the world to access the current, and all previous versions, of the framework, debate about concepts and variables, and collectively decide upon refinements and extensions to be made. We hope that the framework will be connected to a database of individual case studies initiated by colleagues at the Center for Institutional Diversity at Arizona State University and facilitate the uploading of case study information represented in terms of the framework. Our dreams for future joint projects, however, will be greatly facilitated 
if we are able to raise funds by different means. We are now at a stage where without some financial support, it will be difficult to keep up momentum and make further progress.

\section{COMMENT FROM THE EDITORS}

Very sadly Lin passed away shortly after our last meeting in Osnabrück in February 2012. Despite her untimely death the process the SES Club has initiated is continuing. There were several SES Club meetings in the following years, namely in Munich hosted by Claudia Binder in 2012 and in Marburg hosted by Michael Kirk and Thomas Falk in January 2014. The SES Club also met at WOW5, the Workshop on the Ostrom Workshop in June 2014 to discuss the next steps of our joint enterprise and possible funding sources. There are also several subgroups that continue working on ideas generated in the SESClub and beyond, particularly with respect to the creation of SES databases. These are the SESMAD project lead by Michael Cox (Cox 2014) as well as a SES database group comprised of core SES Club members Claudia Binder, Claudia Pahl-Wostl, Thomas Falk, Ulrich Frey and Christian Knieper.

Readers of the special issue interested in the framework and keeping on top of and contributing to discussions of its evolution are encouraged to communicate with us.

\section{LITERATURE CITED}

Baur, I., Binder, C.R., 2013. Adapting to Socioeconomic Developments by Changing Rules in the Governance of Common Property Pastures in the Swiss Alps. Ecology and Society 18.

doi:10.5751/ES-05689-180460

Cox, M. 2014. Applying a social-ecological system framework to the study of the Taos acequia irrigation system. Human Ecology 42(2): 311-324.

Falk, T., Vollan, B.; Kirk, M., 2012. Analysis of material, social, and moral governance in natural resource management in southern Namibia. International Journal of the Commons, [S.1.], v. 6, n. 2, p. 271-301, aug. 2012. ISSN 1875-0281. Available at:

<http://www.thecommonsjournal.org/index.php/ijc/article/view/URN\%3ANBN\%3ANL\%3AUI \%3A10-1-113806/292>. Date accessed: 16 Oct. 2015.

McGinnis, M.D., Ostrom, E., 2014. Social-ecological system framework: initial changes and continuing challenges. Ecology and Society 19. doi:10.5751/ES-06387-190230 


\section{NOTE}

${ }^{1}$ Thanks to Claudia Pahl-Wostl, Jochen Hinkel, and Maja Schlüter for their very helpful suggestions and review of the first draft of this paper. Jochen Hinkel kindly drafted the first version of the last two paragraphs of the text - for which I am deeply appreciative.

${ }^{2}$ Michael Aklin (PIK), Reinette (Oonsie) Biggs (Stockholm Resilience Center), Thomas Bernauer (ETH Zürich), Claudia Binder (University of Zürich), Pieter Bots (Delft University of Technology), Armin Haas (PIK), Jochen Hinkel (PIK), Rolf Kunneke (Delft University of Technology), Carlo Jaeger (PIK), Elinor Ostrom (IU), Maja Schlüter (Princeton University), Jan Senzimir (IIASA), Detlef Sprinz (PIK).

${ }^{3}$ Summary of First SES Club Workshop, p. 1.

${ }^{4}$ Oonsie Biggs (SRC), Claudia Binder (University of Zurich), Pieter Bots (Delft University of Technology), Mattias Finger (EPFL, Lausanne), Carl Folke (SRC), Jochen Hinkel (PIK), Rolf Kunneke (Delft University of Technology), Elinor Ostrom (IU), Claudia Pahl-Wostl (University of Osnabrück), Johan Rockstrom, (SRI), Audun Sandberg (Bodø), Maja Schlüter (Princeton), Jan Sendzimir (IIASA), Detlef Sprinz (PIK), Theo Toonen (Delft University of Technology).

${ }^{5}$ Claudia Binder (University of Graz), Pieter Bots (Delft University of Technology), Mattias Finger (EPFL, Lausanne), Konrad Hagedorn (Humboldt University Berlin), Jochen Hinkel (PIK), Michael Kirk (Marburg University), Rolf Kunneke (Delft University of Technology), Piotr Magnuszewski (IIASA), Elinor Ostrom (IU), Michael McGinnis (IU), Claudia Pahl-Wostl (University of Osnabrück), Audun Sandberg (Bodø), Maja Schlüter (Princeton), Jan Sendzimir (IIASA), Detlef Sprinz (PIK), Theo Toonen (Delft University of Technology).

${ }^{6}$ Claudia Binder (University of Graz), Pieter Bots (Delft University of Technology), Frances Brazier (Delft), Konrad Hagedorn (Humboldt University Berlin), Jochen Hinkel (PIK), Michael Kirk (Marburg University), Christian Knieper (University of Osnabrück), Rolf Kunneke (Delft University of Technology), Elinor Ostrom (IU), Michael McGinnis (IU), Claudia Pahl-Wostl (University of Osnabrück), Audun Sandberg (Bodø), Maja Schlüter (IGB - Leibniz Institute of Freshwater Ecology and Inland Fisheries), Jan Sendzimir (IIASA), Detlef Sprinz (PIK), Theo Toonen (Delft University of Technology). ${ }^{7}$ Ivo Baur (University of Graz), Claudia Binder (University of Graz), Pieter Bots (Delft University of Technology), Frances Brazier (Delft), Claudia Brink (IU), Barbara Cherry (IU), Michael Cox (IU), Tom Evans (IU), Thomas Falk (Marburg University), Mattias Finger (EPFL, Lausanne), Ulrich Frey (University of Giessen), Jochen Hinkel (PIK), Michael Kirk (Marburg University), Rolf Kunneke (Delft University of Technology), Elinor Ostrom (IU), Michael McGinnis (IU), Claudia Pahl-Wostl (University of Osnabrück), Audun Sandberg (Bodø), Maja Schlüter (IGB), Jan Sendzimir (IIASA), Detlef Sprinz (PIK), Theo Toonen (Delft University of Technology).

${ }^{8}$ Claudia Binder (University of Graz), Pieter Bots (Delft University of Technology), Frances Brazier (Delft), Michael Cox (IU), Thomas Falk (Marburg), Gunn Elin Fedreheim (Bodø), Mathias Finger (EPFL, Lausanne), Ulrich Frey (University of Giessen), Camilla Risvoll Godø (Bodø), Konrad Hagedorn (Humboldt University), Jochen Hinkle (PIK), Michael Kirk (Marburg University), Rolf Kunneke (Delft University of Technology), Elinor Ostrom (IU), Audun Sandberg (Bodø), Maja Schlüter (IGB), Theo Toonen (Delft University of Technology).

${ }^{9}$ Claudia Binder (University of Munich), Sandy Bisaro (GCF), Pieter Bots (Delft University of Technology), Frances Brazier (Delft), Michael Cox (IU), Thomas Falk (Marburg), Ulrich Frey (University of Giessen), Konrad Hagedorn (Humboldt University, Berlin), Johannes Halbe (USF) Jochen Hinkle (PIK), Michael Kirk (Marburg University), Kathrin Knüppe (USF), Rolf Kunneke (Delft University of Technology), Michael McGinnis (IU), Elinor Ostrom (IU), Claudia Pahl-Wostl (University of Osnabrück), Audun Sandberg (Bodø), Maja Schlüter (Stockholm Resilience Centre), Jan Senzimir (IIASA), Insa Theesfeld (IAMO). 